\title{
Noradrenergic control of odor recognition in a nonassociative olfactory learning task in the mouse
}

\author{
Alexandra Veyrac, ${ }^{1}$ Véronique Nguyen, ${ }^{2}$ Marc Marien, ${ }^{2}$ Anne Didier, ${ }^{1}$ \\ and François Jourdan ${ }^{1,3}$ \\ ${ }^{1}$ Neurosciences Sensorielles, Comportement, Cognition, CNRS-UMR 5020, Université de Lyon, Université Claude Bernard_Lyon 1, \\ 69366 Lyon, France and Institut Fédératif des Neurosciences de Lyon IFR19, 59 bd Pinel, 69394-Lyon, France; ${ }^{2}$ Division \\ of Neurobiology I, Centre de Recherche Pierre Fabre, 81106 Castres, France
}

The present study examined the influence of pharmacological modulations of the locus coeruleus noradrenergic system on odor recognition in the mouse. Mice exposed to a nonrewarded olfactory stimulation (training) were able to memorize this odor and to discriminate it from a new odor in a recall test performed 15 min later. At longer delays (30 or $60 \mathrm{~min}$ ), the familiar odor was no longer retained, and both stimuli were perceived as new ones. Following a post-training injection of the $\boldsymbol{\alpha}_{2}$-adrenoceptor antagonist dexefaroxan, the familiar odor was still remembered 30 min after training. In contrast, both the $\boldsymbol{\alpha}_{2}$-adrenoceptor agonist UK 14304 and the noradrenergic neurotoxin DSP-4 prevented the recognition of the familiar odor $15 \mathrm{~min}$ after the first exposure. Noradrenaline release in the olfactory bulb, assessed by measurement of the extracellular noradrenaline metabolite normetanephrine, was increased by $62 \%$ following dexefaroxan injection, and was decreased by $38 \%-44 \%$ after treatment with UK 14304 and DSP-4. Performance of mice in the recall test was reduced by a post-training injection of the $\boldsymbol{\beta}$-adrenoceptor antagonist propranolol or the $\boldsymbol{\alpha}_{1}$-antagonist prazosin, thus implicating a role for $\boldsymbol{\beta}$ - and $\boldsymbol{\alpha}_{1}$-adrenoceptors in the facilitating effects of noradrenaline on short-term olfactory recognition in this model.

The ascending noradrenergic (NA) system that originates in the locus coeruleus (LC) innervates all cortical forebrain areas and has been shown to participate in behavioral flexibility, attention, and the facilitation of processing of novel or significant sensory stimuli (Aston-Jones et al. 2000; Berridge and Waterhouse 2003; Bouret and Sara 2004). LC-NA afferents innervate several olfactory cortical areas and appear to play crucial functions in the processing of relevant olfactory information and in several types of olfactory learning tasks in various species. In the newborn rat, olfactory learning associated with early imprinting requires an intact LC-NA system (Moriceau and Sullivan 2004), and injections of $\beta$-adrenoceptor agonists into the olfactory bulb (OB) can mimic the reinforcing properties of a reward associated with an olfactory stimulus (Sullivan et al. 2000; Bordner and Spear 2006). In the adult brain, the LC-NA system has been implicated in some specific forms of olfactory memory (Gervais et al. 1988; Brennan and Keverne 1997), such as learning of the male odor by the female mouse during mating (Rosser and Keverne 1985) or learning of odor preference by sheep for recognition of lambs (Levy et al. 1990). Evidence has also been shown for a participation of the LC-NA system in more classical olfactory conditioning procedures in the rabbit (Gray et al. 1986) and in the mouse (Brennan et al. 1998).

Increases of NA release in the cortices innervated by the LC-NA system have been correlated with associative olfactory conditioning in the mouse OB (Brennan et al. 1998) and posttraining consolidation memory following associative conditioning procedures in the prefrontal cortex (Tronel et al. 2004). $\alpha_{2}$ Adrenoceptor antagonists, such as dexefaroxan, are able to increase NA release in target areas by blockade of pre-synaptic

${ }^{3}$ Corresponding author.

E-mail jourdan@olfac.univ-lyon 1.fr; fax 33-4-37-28-76-01.

Article is online at http://www.learnmem.org/cgi/doi/10.1101//m.708807. inhibitory autoreceptors on LC-NA afferents (Mayer et al. 2001; Veyrac et al. 2005). When given immediately after training, dexefaroxan improves the memory performance of adult rats or mice in passive avoidance conditioning, water maze tasks, and object recognition tests (Chopin et al. 2002).

The present study examined a possible involvement of NA in the retention of olfactory memory in a simple nonrewarded odor recognition task in the mouse. We found that dexefaroxan given immediately after stimulation with a test odor improved the retention of this odor. In contrast, the decrease of NA release resulting from pharmacological treatments with the $\alpha_{2}$ adrenoceptor agonist UK 14304 or the selective noradrenergic neurotoxin DSP-4 was associated with a reduced retention of olfactory memory. Post-synaptic adrenoceptors of the $\alpha_{1}$ - and $\beta$ subtypes were most likely involved in the facilitating effects of $\mathrm{NA}$, since the $\alpha_{1}$-antagonist prazosin and the $\beta$-antagonist propranolol were able to reduce the retention of olfactory memory in the same odor-recognition task.

\section{Results}

Odor recognition test in control mice: Influence of the delay between acquisition and recall

In a preliminary experiment, we verified that carvone and limonene, presented simultaneously in two different holes of the hole-board apparatus (Fig. 1A), were equally explored by mice that had never been previously exposed to these compounds (data not shown). This observation established that mice do not show a preference for either of these two odors at the concentrations used in this study.

During the acquisition test, one of these two odors (carvone or limonene) was present simultaneously in both holes of the hole-board, and the exploration time of mice at each hole was 
A

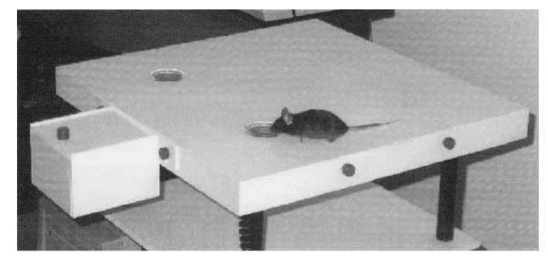

B

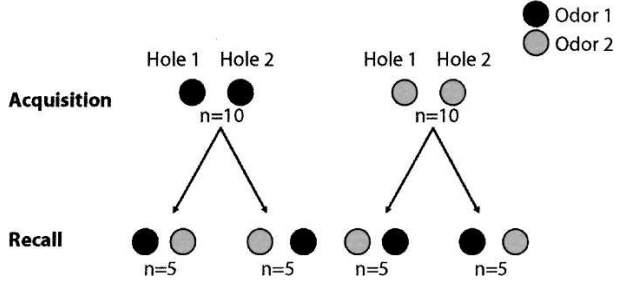

Figure 1. Experimental setup. (A) View of the hole-board for mice specifically designed for olfactory learning tests described in the present study. An odorized piece of polypropylene was placed under shavings at the bottom of each hole. The number of entries of the mouse's nose into each hole and the duration of time of each nose poke were automatically detected with capacitive sensors and recorded through custom-made computer software. (B) In a first 2-min-long acquisition test, both holes were odorized with the same compound and were equally explored by the animals. In a recall test occurring after a delay of 15, 30, or $60 \mathrm{~min}$, one hole was odorized with the odor previously presented in the acquisition test, while the other hole contained a new odorant compound. The placements of the familiar and new odors were randomized in order to avoid place preference bias.

measured (Fig. 1B). As expected, the animals spent the same amount of time exploring each of the two odorized holes (Fig. 2). The recall test consisted of a single trial in which one of the two holes contained the odor presented during the acquisition test, while the other hole contained the new odor to which the animal had never before been exposed. When the delay between the acquisition and the recall tests was $15 \mathrm{~min}$, the exploration time of the hole containing the new odor was significantly longer than the time spent in exploring the hole odorized with the familiar odor (one-sample $t$-test; $p<0.005$ ) (Fig. 2), indicating that the animals remembered the familiar odor and could discriminate the other odor as a new one. At the delays of 30 or 60 min, the animals spent the same time exploring either hole (onesample $t$-test; $p>0.05$ ) (Fig. 2), indicating that they no longer remembered the odor presented during the acquisition test, both odors being considered as unfamiliar at these later times. From these data, it can be inferred that olfactory information relative to a stimulus given in a simple nonrewarded stimulation protocol in normal mice could be retrieved 15 min after training but was lost at the delays of 30 or 60 min post-training.

\section{Improvement of odor recognition by a post-training injection of dexefaroxan}

In contrast to saline-injected control animals that equally explored both holes in the recall test after a 30-min delay, mice that received a single i.p. injection of dexefaroxan $(0.63 \mathrm{mg} / \mathrm{kg}) \mathrm{im}$ mediately at the end of the acquisition session showed a significantly increased exploration of the hole odorized with the new odor (one-sample $t$-test; $p<0.005$ ) (Fig. 3A). This overexploration of the new odor by dexefaroxan-injected animals indicates that they remembered the odor presented in the acquisition test, whereas saline-injected animals had forgotten this test odor after the same 30-min delay. Following a delay of $60 \mathrm{~min}$ after acquisition, dexefaroxan-injected animals equally explored the two odorized holes, indicating that they could no longer remember the test odor, as was also the case for the saline-injected control animals at this same time (one-sample $t$-test; $p>0.05$ ).

General locomotor activity and exploratory behavior were not affected by dexefaroxan since neither the total number of nose pokes into the holes of the hole-board (ANOVA, $\left.F_{(3,46)}=0.230, p=0.875\right)$ (Fig. 3B), nor the mean investigation time of holes (ANOVA, $F_{(3,45)}=0.774, p=0.515$ ) (data not shown) were different in the saline- and dexefaroxan-injected groups.

The level of the extracellular noradrenaline metabolite normetanephrine (NMN) in the OB obtained from a separate group of mice euthanized by high-power head-focused microwave irradiation was used as an index to evaluate the effect of dexefaroxan in modifying NA release in vivo (Wood et al. 1987). As shown in Figure 3C, a single i.p. injection of dexefaroxan resulted in a significant increase in NMN levels in the $\mathrm{OB}$ at $30 \mathrm{~min}(+62 \%$; student's $t$-test, $p=0.0076)$ and $60 \mathrm{~min}$ post-treatment $(+52 \%$; student's $t$-test, $p=0.0025)$, in comparison to the levels measured in saline-injected control mice. The dexefaroxan-induced increase in NMN levels was significantly greater at the 30-min postinjection time point (student's $t$-test, $p=0.026$ ), consistent with the rapid onset and decay of the drug's effect in blocking central $\alpha_{2}$-adrenoceptors in vivo following administration by the i.p. route (Mayer et al. 2001).

\section{Impairment of short-term olfactory recognition by inhibitors of NA release}

When the recall test was performed 15 min after the acquisition test, saline-injected animals recognized the familiar odor and explored more actively the new one (one-sample $t$-test; $p<0.005$ ) (Fig. 4A). After the same delay, mice that received a single i.p. injection of the $\alpha_{2}$-adrenoceptor agonist UK $14304(0.16 \mathrm{mg} / \mathrm{kg})$ immediately after the acquisition session, equally explored the two odorized holes (one-sample $t$-test; $p>0.05$ ), indicating that UK 14304 had interfered with the retention of the odor perceived during the acquisition test. A similar failure of test odor retention

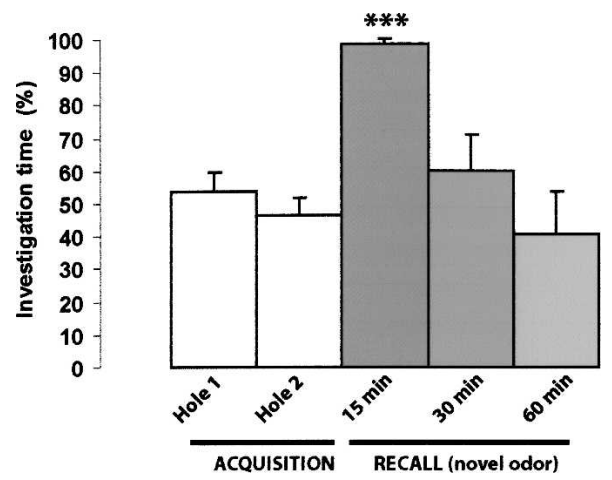

Figure 2. Odor recognition test in control mice. Mice were submitted to the acquisition test ( $2 \mathrm{~min}$ ) with either carvone or limonene present in both holes of the hole-board. The percent investigation times (vertical axis) of the two holes were similar (open bars: "Acquisition," Hole 1 and Hole 2). Immediately following the acquisition test, all the animals received an i.p. injection of vehicle (physiological saline) and were submitted to the recall test after a delay of 15,30 , or 60 min. The solid bars ("Recall - novel odor") represent the mean exploration time of the hole containing the new odor, expressed as a percentage of the total exploration time of the two holes. At the shortest delay $(15 \mathrm{~min})$, the animals spent a significantly greater percentage of time exploring the hole containing the unfamiliar odor than that containing the familiar one (onesample $t$-test; $\left.\left.{ }^{* * *}\right] p<0.005\right)$. At longer delays (30 and $60 \mathrm{~min}$ ), the two holes were equally explored, indicating that mice could no longer remember the familiar odor (one-sample $t$-test; $p>0.05$ ). 


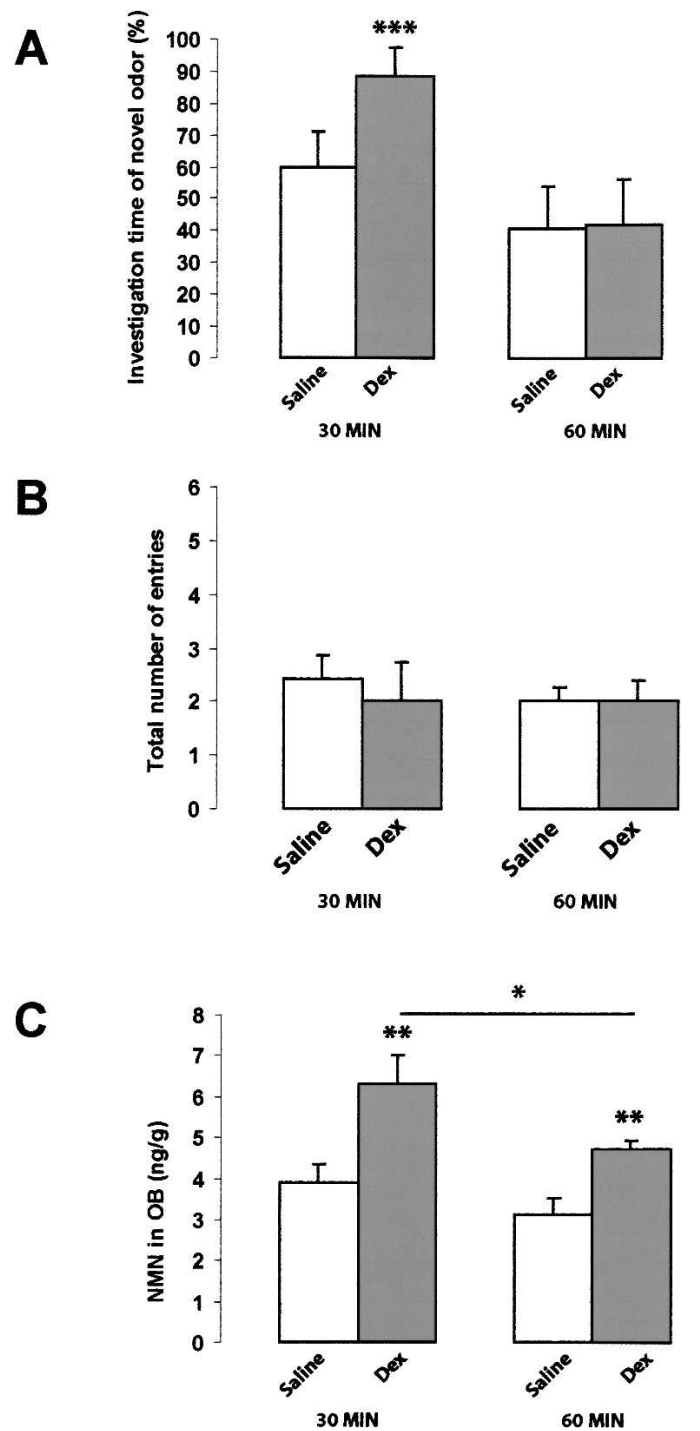

Figure 3. Effects of post-training injection of dexefaroxan on odor recognition and NMN levels in the OB. (A) Mice received an i.p. injection of dexefaroxan $(0.63 \mathrm{mg} / \mathrm{kg}$ ) or vehicle (physiological saline) immediately after the acquisition test with either carvone or limonene exposure. $(A)$ The investigation time of the hole containing the new odorant, expressed as a percentage of the total investigation time of both odorized holes, during a recall test performed 30 or 60 min after the acquisition test. At the delay of $30 \mathrm{~min}$, dexefaroxan-injected mice spent a longer time investigating the new odorant (one-sample $t$-test; $\left[{ }^{* *}\right] p<0.005$ ), indicating that they remembered the familiar one. At the same time, the vehicle (saline) injected animals explored both holes equally, indicating that they no longer remembered the familiar odor. At the longer delay of $60 \mathrm{~min}$, saline- and dexefaroxan-injected animals spent the same time exploring the holes containing the familiar and unfamiliar odors, indicating that they no longer remembered the familiar odor (one-sample $t$-test; $p>0.05$ ). (B) Total number of nose entries into the holes of the hole-board. The general locomotor activity and exploratory behavior were not affected by dexefaroxan (ANOVA $\left.F_{(3,46}=0.230, p=0.875\right)$. (C) HPLC measurements of normetanephrine (NMN), the extracellular metabolite of NA, in the OB of saline vehicle and dexefaroxan-injected mice, 30 or 60 min after i.p. injection. At the 30-min and 60 -min delays, the levels of NMN were significantly higher in the dexefaroxan-treated groups versus saline-injected mice, indicating that the drug had increased NA release in the OB (student's t-test, $p=0.0076$ and $p=0.0025$, respectively). However, the level of NMN was significantly lower at $60 \mathrm{~min}$ than at $30 \mathrm{~min}$ after injection of dexefaroxan (student's $t$-test, $p=0.026$ ), indicating that the drug effect was probably decreasing with post-injection time, which would be consistent with the rapid onset and decay of the drug's effect in blocking central $\alpha 2$ adrenoceptors in vivo following administration by the i.p. route (Mayer et al. 2001). was observed in animals that had received a single i.p. injection of the noradrenergic neurotoxin DSP-4 $24 \mathrm{~h}$ before the acquisition test (one-sample $t$-test; $p>0.05$ ). A post-training injection of DSP4-treated animals with dexefaroxan was unable to restore the retrieval of the test odor (one-sample $t$-test; $p>0.05$ ).

The pharmacologically induced deficits in recall could not be attributed to potential drug effects on locomotor activity or exploratory activity, since neither the mean number of nose pokes in the holes of the board (ANOVA, $F_{(3,50)}=1.531$, $p=0.218$ ) (Fig. 4B), nor the mean investigation time of holes (ANOVA, $F_{(3,50)}=2.084, p=0.114$ ) (data not shown) were different between drug-treated groups and saline-injected control animals.

In a separate study, the treatments with UK 14304 and DSP-4 were found to produce significant reductions of $38 \%$ and $44 \%$, respectively, in NMN levels in the $\mathrm{OB}$ at 15 -min postinjection (ANOVA, $F_{(3,22)}=7.807, p=0.001$; Tukey post hoc, $p=0.006, p=0.009$, and $p=0.001$, respectively) (Fig. 4C).

\section{Impairment of short-term olfactory recognition by propranolol ( $\beta$-adrenoceptor antagonist) and prazosin $\left(\boldsymbol{\alpha}_{1}\right.$-adrenoceptor antagonist)}

Three experimental groups of mice received a post-acquisition injection of either the $\alpha_{1}$-adrenoceptor antagonist prazosin (1 or $1.5 \mathrm{mg} / \mathrm{kg}$ i.p.), or the $\beta$-adrenoceptor antagonist propranolol (10 $\mathrm{mg} / \mathrm{kg}$ i.p.), while a control group received a saline injection. At the delay of $15 \mathrm{~min}$ following the acquisition session, saline- and prazosin-injected animals at the lower dose $(1 \mathrm{mg} / \mathrm{kg})$ displayed a similar overexploration of the new odor in the recall test (onesample $t$-test, $p<0.005$ and $p<0.05$, respectively) (Fig. 5A). In contrast, prazosin- $(1.5 \mathrm{mg} / \mathrm{kg})$ and propranolol-injected animals explored equally the two holes (one-sample $t$-test, $p>0.05$ ) (Fig. $5 \mathrm{~A})$, indicating that both drugs interfered with the retention of the familiar odor.

As previously observed in the other drug-injected groups, neither propranolol nor prazosin at the doses used here significantly influenced the number of nose pokes in the holes (ANOVA, $\left.F_{(3,50)}=0.573, p=0.635\right)$ (Fig. 5B) or the mean investigation time of holes (ANOVA, $F_{(3,35)}=0.376, p=0.696$ ) (data not shown), indicating that locomotor activity and exploratory behavior of the animals were not affected by the drugs.

\section{Discussion}

In the present study, we found that NA release by the LC-NA system was associated with promoting the recognition of a familiar odor, and that this effect was most likely mediated by $\alpha_{1}$ and $\beta$-adrenoceptors. In the protocol used in this study, an odor previously provided within a unique acquisition trial is expected to be less explored than a new one in a second recall trial where the familiar and the new odors are simultaneously accessible to the animals. The involvement of NA in the modulation of olfactory recognition in such tasks has previously been suggested by the observation that dishabituation to urine odor in the rat is altered by a previous injection with the catecholaminergic neurotoxin 6-OHDA (Guan et al. 1993a). Furthermore, the increased level of NA in the adult rat OB that follows a local injection of oxytocin is associated with an improvement in the social olfactory recognition of a familiar juvenile male versus a nonfamiliar one (Dluzen et al. 2000). Since we selected pure odorant compounds devoid of any biological significance as olfactory stimuli, our data establish that NA is necessary for the consolidation of short-term olfactory memory in olfactory recognition tasks even outside the specific context of social recognition. Since dexefaroxan was injected immediately after the learning session, its promnesic effect occurred by facilitating the memory consolida- 
A
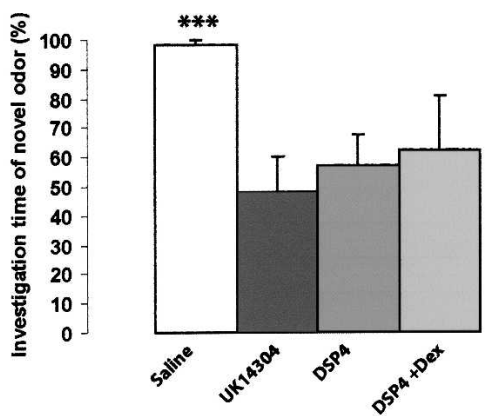

B

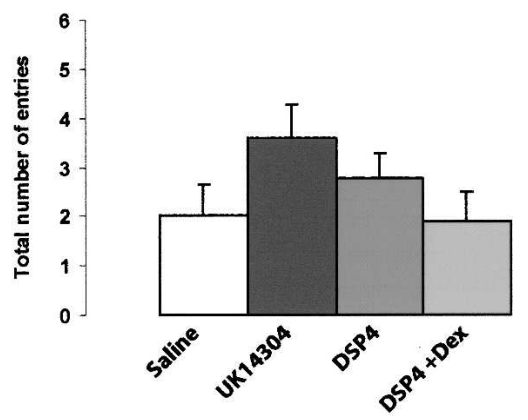

C

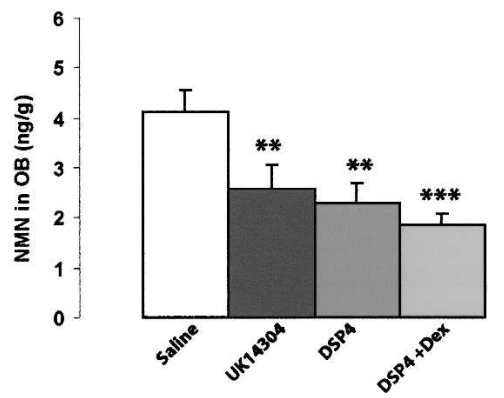

Figure 4. Impairment of short-term (15 $\mathrm{min})$ odor recognition following inhibition of NA release. $(A)$ Histograms represent the mean investigation time of the new odor during a recall test performed 15 min after the acquisition test. As previously shown in Figure 2, saline-injected mice remembered the familiar odor and spent a significantly longer time in exploring the new odor than the familiar one (one-sample $t$-test; [***] $p<0.005$ ). Following a post-training injection of the $\alpha_{2}$-adrenoreceptor agonist UK 14304, mice spent an equal amount of time exploring the two holes, indicating that they did not remember the familiar odor (onesample $t$-test; $p>0.05$ ). A similar result was obtained with animals that had received a DSP-4 pre-treatment $24 \mathrm{~h}$ before, with a subsequent treatment with dexefaroxan or saline vehicle immediately after the acquisition test (one-sample $t$-test; $p>0.05$ ). (B) Total number of nose entries into the holes of the hole-board. The general locomotor activity and exploratory behavior were not affected by UK 14304 or DSP-4 injections (ANOVA $F_{(3,50)}=1.531, p=0.218$ ). (C) HPLC measurement of normetanephrine in the $\mathrm{OB}$ of mice receiving the same drug treatments as described in panel $A$. When compared with saline-injected animals, all of the drug-injected animals had a significantly lower level of NMN in the OB (ANOVA $F_{(3,22)}=7.807, p=0.001$, Tukey post hoc, $\left[{ }^{* *}\right] p=0.006$; $\left[{ }^{* *}\right] p=0.009$, and $\left[{ }^{* * *}\right] p=0.001$ compared to saline-injected mice, respectively), indicative of a reduced release of NA in this structure. NMN levels in DSP-4 pre-treated mice were not altered 15 min after the acute treatment with dexefaroxan or vehicle. Note the correlation between $(C)$ the decrease of NMN levels in the OB and $(A)$ the failure of short-term odor recognition in the recall test.

tion/retention process, and not the acquisition. This is entirely consistent with the effect of dexefaroxan to improve object recognition performance in the mouse in a very similar protocol (Chopin et al. 2002). Thus, for odor as for object recognition, dexefaroxan appears to significantly facilitate the memory consolidation and/or retention process(es). The different ranges of retention times observed for odors (15-30 $\mathrm{min}$ in the present study) versus objects (1-4 h in the study by Chopin et al. 2002) are possibly related to differences in modalities of detection, objects being detected through visual and somato-sensory input and perhaps memorized more easily than simple pure odorants having no biological salience to the animals. In both cases, dexefaroxan most likely improves the retention of sensory information by its action as a highly selective $\alpha_{2}$-adrenoceptor antagonist and its effect to increase the NA release in vivo by blockade of inhibitory $\alpha_{2}$-autoreceptors. In the present experiments, dexefaroxan-injected animals were able to recognize a previously presented odor at $30 \mathrm{~min}$ but not at $60 \mathrm{~min}$ after drug injection, although the level of NMN in the OB was significantly elevated compared to saline controls at both time points. However, the drug-induced increase in NMN levels at 60 min was significantly lower than at $30 \mathrm{~min}$, suggesting that the maintenance of odor recognition by dexefaroxan in this test is dependent on a critical threshold level of NA release that can be attained or surpassed only within a relatively short time $(<60 \mathrm{~min})$ after drug administration.

Consistent with the promnesic and NA-releasing effects of the $\alpha_{2}$-adrenoceptor antagonist dexefaroxan in the present

A

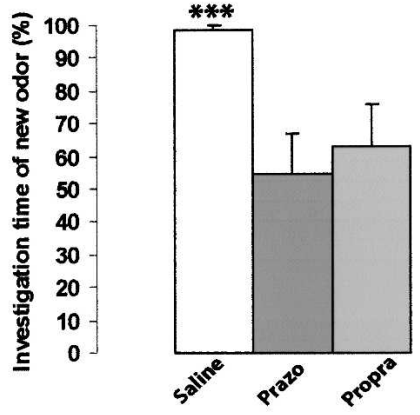

B

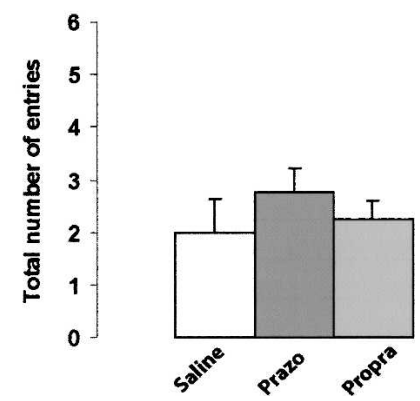

Figure 5. Effects of post-training injections of propranolol or prazosin on short-term (15 min) odor recognition. $(A)$ Histograms represent the mean investigation times of the new odor in a recall test performed 15 min after the acquisition test. As described in Figure 2, mice that received a saline injection immediately following the acquisition test spent a significantly longer time investigating the hole containing the new odor (one-sample $t$-test; ${ }^{\left.{ }^{* * *}\right]} p<0.005$ ), indicating a recognition of the familiar one. In contrast, mice injected with prazosin $(1.5 \mathrm{mg} / \mathrm{kg})$ or with the $\beta$-adrenoreceptor antagonist propranolol $(10 \mathrm{mg} / \mathrm{kg})$ immediately after acquisition equally explored both holes (one-sample $t$-test; $p>0.05$ ), indicating that they no longer recognized the familiar odor. $(B)$ Total number of nose entries into the holes of the hole-board. Neither propranolol nor prazosin at the doses used here $(1.5$ and $10 \mathrm{mg} / \mathrm{kg}$, respectively) significantly influenced the locomotor activity and exploratory behavior of mice (ANOVA, $F_{(3,50)}=0.573, p=0.635$ ). 
study, we have also demonstrated that the $\alpha_{2}$-adrenoceptor agonist UK 14304 was able to reduce NA release in the OB and to simultaneously interfere with the retention of olfactory memory. These observations are reminiscent of the alterations of olfactory recognition abilities that followed the inactivation of the NA system with 6-OHDA (Guan et al. 1993a) or MPTP (Dluzen and Kreutzberg 1993) in habituation/dishabituation tasks involving social olfactory cues from animals of the same species. Our data also demonstrate that lesions of the LC-NA system can alter the consolidation of olfactory memory even for some olfactory stimuli that have no biological significance for the animal. When dexefaroxan was administered to animals that had their LC-NA system previously lesioned with DSP-4 (resulting in a $44 \%$ reduction in levels of NMN in the $\mathrm{OB}$ ), neither recall performance nor NMN levels in the OB were enhanced. These observations indicate that the promnesic effects of dexefaroxan were dependent on an intact LC-NA system (i.e., dexefaroxan was unable to restore a normal level of NA release to balance the amnesic effects of DSP-4) and were thus most likely due to a pre-synaptic NAreleasing action (through blockade of inhibitory autoreceptors) rather than to a blockade of $\alpha_{2}$-adrenoceptors postsynaptic to NA afferent inputs.

The influence of NA on cortical neurons is mediated by the postsynaptic $\alpha_{1}$ - and $\beta$-adrenoceptors that have been clearly implicated in memory consolidation processes (Sirvio and MacDonald 1999; Gibbs and Summers 2002). Adrenoceptors of the $\alpha_{1}$ and $\beta$-subtypes are very abundant in the olfactory bulb (McCune et al. 1993; Woo and Leon 1995; Domyancic and Morilak 1997), where they seem able to mediate NA-induced modulations of neuronal activity in the newborn rat (Harley et al. 2006). Previous studies have established a role of $\beta$-adrenoreceptors in mediating learning of odor preference in the rat pup (Wilson et al. 1994), learning of the odor of newborn lambs by parturient ewes (Levy et al. 1990), and the transient changes in EEG patterns associated with olfactory conditioning in the rabbit (Gray et al. 1986). The results obtained in the present study provide evidence for the involvement of both $\alpha_{1}$ - and $\beta$-adrenoceptors in the synaptic mechanisms by which NA influences the short-term consolidation of nonassociative olfactory memory in the adult mouse. Consistently with this hypothesis, the $\beta$-adrenoreceptor antagonist propranolol has been shown to drastically reduce the expression of c-fos that is induced in granule cells of the rat $\mathrm{OB}$ during familiarization to a novel olfactory stimulus (Sallaz and Jourdan 1996; Montag-Sallaz and Buonviso 2002). Post-synaptic $\alpha_{1}$-adrenoceptors have also been implicated in learning-related effects of NA release in the olfactory system (Kaba and Keverne 1988; Dluzen et al. 2000), and they have been shown to mediate in the adult $\mathrm{OB}$ the NA-induced increase of mitral cells' response to weak olfactory stimuli (Mouly et al. 1995; Ciombor et al. 1999). Finally, a recent study proposed a synaptic model accounting for the complex direct or indirect influences of adrenoceptors on mitral and granule cells activities in the $\mathrm{OB}$ (Harley et al. 2006). Our current data are consistent with this model and support complementary involvements of $\alpha_{1}$ - and $\beta$-adrenoceptors in the formation of olfactory memory in the adult OB. In addition, we cannot rule out a possible interaction between $\alpha_{1^{-}}$and $\beta$ adrenoceptors, as demonstrated in the basolateral amygdala, where $\alpha 1$-adrenoceptors affect memory storage by modulating the $\beta$-adrenoceptors' activation (Ferry et al. 1999). However, this hypothesis deserves further investigations in the olfactory system.

Since an efficient detection of olfactory stimuli is a prerequisite for olfactory recognition, it could be argued that potential drug-induced alterations in odor detection performance might have influenced the learning abilities of mice. This hypothesis is unlikely since several studies have shown that NA depletion with
6-OHDA has no effect on the detection of odorant compounds, at least in rats (Doty et al. 1988; Guan et al. 1993a). Furthermore, propranolol administration into the OB does not impair the ability of rabbits to detect a new odor (Gray et al. 1986). Since the recognition task used in this study involved a discrimination between the familiar and the new odor in the recall session, we have also to consider the hypothesis that the reduced release of NA (by UK 14304), or its depletion (by DSP-4), or the blockade of post-synaptic receptors (with prazosin or propranolol) might somehow have interfered with the olfactory discrimination abilities in the recall test and could have thus indirectly influenced the memory performances. However, a recent study (Doucette et al. 2007) has demonstrated that the blockade of both $\alpha$ - and $\beta$-adrenergic receptors did not impair the discrimination of two odorant compounds differing substantially by their chemical and perceptual properties. Since the odorants selected in our study (carvone and limonene) can be easily discriminated according to the very distinct patterns of spatial glomerular activation that they induce in the OB (Linster et al. 2001), we can assume that the drugs used in our study were not capable of significantly affecting their discrimination. Furthermore, the improvement of olfactory memory retention induced by dexefaroxan treatment cannot be explained by a better discrimination of the odorant compounds since this discrimination was already easily attained by the animals under standard conditions. Thus, we are left to assume that the opposite effects of dexefaroxan (facilitation) and UK 14304 or DSP-4 (attenuation) on recognition performances in the recall test were most likely due to a direct influence of NA release on synaptic events participating in the consolidation of the olfactory memory that occurred in olfactory cortices, including the $\mathrm{OB}$.

The olfactory cortices, and specially the olfactory bulb, are densely innervated by other neuromodulatory systems including the basal forebrain cholinergic system (Macrides et al. 1981; Le Jeune et al. 1995), and the serotonergic system originating in the nucleus raphe dorsalis (McLean and Shipley 1987). These afferent systems could both interact with the LC-NA system and influence olfactory learning. For example, dexefaroxan is able to increase acetylcholine outflow in the frontal cortex of the rat (Tellez et al. 1999), an effect that is dependent on the state of integrity of the LC-NA system. The colocalization of $5 \mathrm{HT}_{2 \mathrm{~A}}$ receptors and $\beta$-adrenoceptors in mitral cells has been shown to support a coregulation of cAMP level and to allow a synergistic involvement of these receptors in odor preference learning in the rat pup (Yuan et al. 2003). Thus, interactions occurring at the cellular level could influence the role of the NA system in the processing of olfactory information. However, contributions of the cholinergic and/or serotonergic systems to the noradrenergic modulation of nonassociative olfactory memory retention seem relatively unimportant since combined lesions of the cholinergic and serotonergic systems did not alter the recognition of a test odor $30 \mathrm{~min}$ after the first presentation in a habituation/ dishabituation task (Wirth et al. 2000).

Previous studies have demonstrated that dexefaroxan exerts neuroprotective effects against degenerative structural changes in the brain (Debeir et al. 2002; Veyrac et al. 2005) and reduces the memory deficits resulting from excitotoxic and devascularization-induced brain lesions (Chopin et al. 2002, 2004). Thus, the present findings establish that in addition to its previously demonstrated role in different stages of memory consolidation (Tronel et al. 2004), or in the long-term functional maintenance of behaviors that depend on the integrity of certain neuronal networks (Chopin et al. 2004), NA is necessary for the short-term retention of olfactory memory in nonassociative odor recognition tasks in the adult mouse. These findings provide an additional illustration of the multiple and complex roles by 
which the LC-NA system influences memory in the mammalian brain.

\section{Materials and Methods}

\section{Animals}

For all procedures, animals were handled and cared for in accordance with the Guide for the Care and Use of Laboratory Animals (National Research Council 1996) and the European Directive $86 / 609$. The experimental protocols were carried out in compliance with local ethical committee guidelines for animal research. Male C57BL/6J mice (Charles River Laboratories, Domaine des Oncins, France) ( $n=200$ for behavior experiments, and $n=47$ for HPLC measurements) 8-10 wk of age were housed in groups of five and had free access to water and food at $20^{\circ} \mathrm{C}-24^{\circ} \mathrm{C}$ under a 12-h light/dark cycle (lights on at 7:00 am).

\section{Experimental setup and olfactory recognition task}

For the present study, an odorized hole-board for mice was specifically designed and constructed, as shown in Figure 1A and previously described (Mandairon et al. 2006). For the experiments described herein, two holes $(3-\mathrm{cm}$ diameter and $4.5-\mathrm{cm}$ deep) were used. A polypropylene swab embedded in a fine plastic mesh and containing $20 \mu \mathrm{L}$ of the diluted odors (1:10) was placed at the bottom of the holes and covered with wood shavings. The acquisition test (one session) consisted of one odor [(+)limonene or $(-)$ carvone] (Sigma-Aldrich) being presented in both holes for a 2-min period. In a preliminary experiment, where the same pair of odors was presented simultaneously (one odor in each hole) in a one-trial test, mice spent the same amount of time exploring either hole, indicating that there was no preference for one of the two odors (data not shown). The recall test consisted of a second 2-min session in which one hole was odorized with the previously presented odor and the other hole with a new odor (Fig. 1B). The delay between acquisition and recall tests was 15,30 , or $60 \mathrm{~min}$. Each test (acquisition or recall) lasted 2 min during which time the number of entries of the mouse's nose into the holes and the exploration time of each nose poke were automatically detected by capacitive sensors and acquired with custom-made computer software. In the recall test, the cumulated exploration time of each hole was converted as a percentage of the total exploration time of the two holes. Animals were considered to have remembered the familiar odor when they spent less time exploring the hole containing it, relative to the time spent exploring the hole containing the new odor. Equal exploration times of both holes during the recall test were considered to indicate that mice did not remember the familiar odor. The two odors were used alternatively during acquisition or recall and presented randomly in each of the two holes to avoid place preference bias (Fig. 1B).

\section{Drugs}

Dexefaroxan (2-[2-ethyl-2,3-dihydrobenzofuranyl]-2 imidazoline) hydrochloride and UK 14304 [5-bromo- $\mathrm{N}$-(4,5-dihydro-1-Himidazol-2-yl)-6-quinoxalinamine] tartrate were synthesized and provided by the Center de Recherche Pierre Fabre, Castres, France. The dose and route of administration $(0.63 \mathrm{mg} / \mathrm{kg}$ i.p.) used here for dexefaroxan, a selective antagonist of $\alpha_{2}$ adrenoceptors, has previously been shown to increase the release of NA in the cortex and the $\mathrm{OB}$ of the adult mouse in vivo (Mayer et al. 2001, 2003; Veyrac et al. 2005). The dose and route of administration used here for UK 14304 (0.16 mg/kg i.p.), a selective $\alpha_{2}$-adrenoceptor agonist with high intrinsic activity (Pauwels et al. 2001), has been previously shown to reduce cortical NA release in vivo (van Veldhuizen et al. 1993). Prazosin hydrochloride and propranolol hydrochloride were obtained from SigmaAldrich (Saint Quentin, France) and used at doses (prazosin 1.5 $\mathrm{mg} / \mathrm{kg}$ and propranolol $10 \mathrm{mg} / \mathrm{kg}$ ) that were found effective after acute i.p. injection in the mouse (Sallaz and Jourdan 1996; Knauber and Muller 2000). All drugs were dissolved in 0.9\% ster- ile saline (vehicle) and injected i.p. immediately after the acquisition session. Control mice received a single i.p. injection of the vehicle at the same time. DSP-4 ( $N$-[2-chloroethyl]- $N$-ethylbromo-benzylamine; Sigma-Aldrich), a selective noradrenergic neurotoxin that produces a long-term depletion of NA in mouse cortical structures (Guan et al. 1993b; Cosi and Marien 1998), was injected i.p. at the dose of $50 \mathrm{mg} / \mathrm{kg}, 24 \mathrm{~h}$ before the acquisition session. This dose and post-treatment delay has been found in a separate series of experiments (not presented) to result in a $68 \%$ reduction of tissue levels of NA in the OB.

\section{Experimental groups}

The experimental groups used in this study are summarized in Table 1 . Animals ( $n=20$ per group) were first submitted to the acquisition (training) trial, then received a saline or drug injection immediately thereafter, and were next submitted to the recall test after a delay of 15,30 , or $60 \mathrm{~min}$. Two groups of animals that received a pre-treatment with DSP- $424 \mathrm{~h}$ beforehand were tested in the recall session 15 min after a post-training injection of either dexefaroxan or saline vehicle.

\section{Measurement of normetanephrine (NMN)}

The measurement of the extracellular NA metabolite normetanephrine (NMN) in brain tissue of animals euthanized by highpower head-focused microwave irradiation has been validated as a reliable quantitative index of NA release in vivo (Wood et al. 1987). The microwaving procedure provides a rapid, noninvasive, and complete fixation (heat-inactivation of enzymes) of the brain in situ, so that accurate determinations of bioanalytes (including $\mathrm{NMN}$ ) that are susceptible to major post-mortem changes can be performed (Wood et al. 1987). To evaluate drug effects on NMN levels in the OB, eight groups of naive mice (five to seven mice per group) received a single i.p. injection of UK $14304(0.16 \mathrm{mg} / \mathrm{kg})$, dexefaroxan $(0.63 \mathrm{mg} / \mathrm{kg})$, or saline vehicle (control) and were sacrificed 15,30 , or 60 min later by highpower head-focused microwave irradiation $(3.8 \mathrm{~kW}, 2450 \mathrm{MHz}$, 0.9 sec; Sacron Model 8000; SAIREM). Two groups of mice pretreated $24 \mathrm{~h}$ in advance with a single injection of DSP-4 (50 $\mathrm{mg} / \mathrm{kg}$ i.p.) were injected with saline vehicle or dexefaroxan $(0.63$ $\mathrm{mg} / \mathrm{kg}$ i.p.) and were killed by the microwaving procedure $15 \mathrm{~min}$ later. The $\mathrm{OB}$ were dissected from the microwave-fixed brain, and the levels of NMN in perchloric acid extracts of tissue samples were quantified using HPLC with electrochemical detection, as previously described (Cosi and Marien 1998).

\section{Statistical analysis}

In the odor recognition test, the time spent by each animal exploring each hole was expressed as a percentage of the total exploration time in each test (acquisition and recall). Individual values were averaged within each experimental group, and onesample $t$-tests were used to test the 50\% hypothesis (random exploration). Data are expressed as mean \pm SEM.

In order to evaluate the level of general exploratory behavior

Table 1. Experimental groups for behavior experiments

\begin{tabular}{lll}
$\begin{array}{l}\text { Post-training } \\
\text { delay }\end{array}$ & $\begin{array}{c}\text { Pre-training } \\
\text { treatment }\end{array}$ & Post-training treatment \\
\hline $15 \mathrm{~min}$ & & Vehicle \\
$30 \mathrm{~min}$ & & Vehicle \\
$60 \mathrm{~min}$ & Vehicle \\
$30 \mathrm{~min}$ & Dexefaroxan $(0.63 \mathrm{mg} / \mathrm{kg})$ \\
$60 \mathrm{~min}$ & Dexefaroxan $(0.63 \mathrm{mg} / \mathrm{kg})$ \\
$15 \mathrm{~min}$ & & UK $14304(0.16 \mathrm{mg} / \mathrm{kg})$ \\
$15 \mathrm{~min}$ & & Vehicle \\
$15 \mathrm{~min}$ & $\mathrm{DSP4}(50 \mathrm{mg} / \mathrm{kg})$ & Dexefaroxan $(0.63 \mathrm{mg} / \mathrm{kg})$ \\
$15 \mathrm{~min}$ & DSP4 $(50 \mathrm{mg} / \mathrm{kg})$ & Prazosin $(1.5 \mathrm{mg} / \mathrm{kg})$ \\
$15 \mathrm{~min}$ & & Propranolol $(10 \mathrm{mg} / \mathrm{kg})$ \\
\hline
\end{tabular}

Drug or vehicle (physiological saline) treatments were administered by i.p. injection in a volume of $10 \mathrm{~mL} / \mathrm{kg}$ body weight. 
of mice after drug treatments, the total number of nose-poke entries in the two holes during the recall test was measured (mean \pm SEM). Data were compared using one-way analysis of variance, with the drug treatment as the factor, followed by a Tuckey post hoc test for comparisons between treated mice and saline-injected mice.

For the NMN measurements, data are expressed as nanogram per gram of tissue weight (mean \pm SEM). Differences between treatment groups were analyzed using either a student's $t$-test or one-way analysis of variance followed by a Tukey post hoc test for comparisons between treated mice and salineinjected mice. A $P$-value of 0.05 was used as the level for statistical significance.

\section{Acknowledgments}

This work was supported by the Région Rhône-Alpes ("Emergence" program - fellowship to A.V.) and by the Institut de Recherche Pierre Fabre. The authors are grateful to Philippe Chopin (Centre de Recherche Pierre Fabre) for helpful discussions.

\section{References}

Aston-Jones, G., Rajkowski, J., and Cohen, J. 2000. Locus coeruleus and regulation of behavioral flexibility and attention. Prog. Brain Res. 126: $165-182$.

Berridge, C.W. and Waterhouse, B.D. 2003. The locus coeruleus-noradrenergic system: Modulation of behavioral state and state-dependent cognitive processes. Brain Res. Brain Res. Rev. 42: $33-84$.

Bordner, K.A. and Spear, N.E. 2006. Olfactory learning in the one-day old rat: Reinforcing effects of isoproterenol. Neurobiol. Learn. Mem. 86: $19-27$.

Bouret, S. and Sara, S.J. 2004. Reward expectation, orientation of attention and locus coeruleus-medial frontal cortex interplay during learning. Eur. J. Neurosci. 20: 791-802.

Brennan, P.A. and Keverne, E.B. 1997. Neural mechanisms of mammalian olfactory learning. Prog. Neurobiol. 51: 457-481.

Brennan, P.A., Schellinck, H.M., de la Riva, C., Kendrick, K.M., and Keverne, E.B. 1998. Changes in neurotransmitter release in the main olfactory bulb following an olfactory conditioning procedure in mice. Neuroscience 87: 583-590.

Chopin, P., Colpaert, F.C., and Marien, M. 2002. Effects of acute and subchronic administration of dexefaroxan, an $\alpha_{2}$-adrenoceptor antagonist, on memory performance in young adult and aged rodents. J. Pharmacol. Exp. Ther. 301: 187-196.

Chopin, P., Debeir, T., Raisman-Vozari, R., Colpaert, F.C., and Marien, M.R. 2004. Protective effect of the $\alpha_{2}$-adrenoceptor antagonist, dexefaroxan, against spatial memory deficit induced by cortical devascularization in the adult rat. Exp. Neurol. 185: 198-200.

Ciombor, K.J., Ennis, M., and Shipley, M.T. 1999. Norepinephrine increases rat mitral cell excitatory responses to weak olfactory nerve input via $\alpha_{1}$ receptors in vitro. Neuroscience 90: 595-606.

Cosi, C. and Marien, M. 1998. Decreases in mouse brain $\mathrm{NAD}^{+}$and ATP induced by 1-methyl-4-phenyl-1,2,3,6-tetrahydropyridine (MPTP): Prevention by the poly(ADP-ribose) polymerase inhibitor, benzamide. Brain Res. 809: 58-67.

Debeir, T., Marien, M., Chopin, P., Martel, J.C., Colpaert, F., and Raisman-Vozari, R. 2002. Protective effects of the $\alpha_{2}$-adrenoceptor antagonist, dexefaroxan, against degeneration of the basalocortical cholinergic system induced by cortical devascularization in the adult rat. Neuroscience 115: 41-53.

Dluzen, D.E. and Kreutzberg, J.D. 1993. 1-Methyl-4-phenyl-1,2,3,6tetrahydropyridine (MPTP) disrupts social memory/recognition processes in the male mouse. Brain Res. 609: 98-102.

Dluzen, D.E., Muraoka, S., Engelmann, M., Ebner, K., and Landgraf, R. 2000. Oxytocin induces preservation of social recognition in male rats by activating $\alpha$-adrenoceptors of the olfactory bulb. Eur. $J$. Neurosci. 12: 760-766.

Domyancic, A.V. and Morilak, D.A. 1997. Distribution of $\alpha_{1 \mathrm{~A}}$ adrenergic receptor mRNA in the rat brain visualized by in situ hybridization. $J$. Comp. Neurol. 386: 358-378.

Doty, R.L., Ferguson-Segall, M., Lucki, I., and Kreider, M. 1988. Effects of intrabulbar injections of 6-hydroxydopamine on ethyl acetate odor detection in castrate and non-castrate male rats. Brain Res. 444: $95-103$.

Doucette, W., Milder, J., and Restrepo, D. 2007. Adrenergic modulation of olfactory bulb circuitry affects odor discrimination. Learn. Mem. 14: $539-547$.

Ferry, B., Roozendaal, B., and McGaugh, J.L. 1999. Basolateral amygdala noradrenergic influences on memory storage are mediated by an interaction between $\beta$ - and $\alpha_{1}$-adrenoceptors. J. Neurosci. 19: 5119-5123.

Gervais, R., Holley, A., and Kerverne, R. 1988. The importance of central noradrenergic influences on the olfactory bulb in the processing of learned olfactory cues. Chem. Senses 13: 3-12.

Gibbs, M.E. and Summers, R.J. 2002. Role of adrenoceptor subtypes in memory consolidation. Prog. Neurobiol. 67: 345-391.

Gray, C.M., Freeman, W.J., and Skinner, J.E. 1986. Chemical dependencies of learning in the rabbit olfactory bulb: Acquisition of the transient spatial pattern change depends on norepinephrine. Behav. Neurosci. 100: 585-596.

Guan, X., Blank, J., and Dluzen, D. 1993a. Depletion of olfactory bulb norepinephrine by 6-OHDA disrupts chemical cue but not social recognition responses in male rats. Brain Res. 622: 51-57.

Guan, X., Blank, J.L., and Dluzen, D.E. 1993b. Role of olfactory bulb norepinephrine in the identification and recognition of chemical cues. Physiol. Behav. 53: 437-441.

Harley, C.W., Darby-King, A., McCann, J., and McLean, J.H. 2006. $\beta_{1}$-Adrenoceptor or $\alpha_{1}$-adrenoceptor activation initiates early odor preference learning in rat pups: Support for the mitral cell/cAMP model of odor preference learning. Learn. Mem. 13: 8-13.

Kaba, H. and Keverne, E.B. 1988. The effect of microinfusions of drugs into the accessory olfactory bulb on the olfactory block to pregnancy. Neuroscience 25: 1007-1011.

Knauber, J. and Muller, W.E. 2000. Subchronic treatment with prazosin improves passive avoidance learning in aged mice: Possible relationships to $\alpha_{1}$-receptor up-regulation. J. Neural Transm. 107: $1413-1426$.

Le Jeune, H., Aubert, I., Jourdan, F., and Quirion, R. 1995. Comparative laminar distribution of various autoradiographic cholinergic markers in adult rat main olfactory bulb. J. Chem. Neuroanat. 9: 99-112.

Levy, F., Gervais, R., Kindermann, U., Orgeur, P., and Piketty, V. 1990. Importance of $\beta$-noradrenergic receptors in the olfactory bulb of sheep for recognition of lambs. Behav. Neurosci. 104: 464-469.

Linster, C., Johnson, B.A., Yue, E., Morse, A., Xu, Z., Hingco, E.E., Choi, Y., Choi, M., Messiha, A., and Leon, M. 2001. Perceptual correlates of neural representations evoked by odorant enantiomers. $J$. Neurosci. 21: 9837-9843.

Macrides, F., Davis, B.J., Youngs, W.M., Nadi, N.S., and Margolis, F.L. 1981. Cholinergic and catecholaminergic afferents to the olfactory bulb in the hamster: A neuroanatomical, biochemical, and histochemical investigation. J. Comp. Neurol. 203: 495-514.

Mandairon, N., Sacquet, J., Garcia, S., Ravel, N., Jourdan, F., and Didier, A. 2006. Neurogenic correlates of an olfactory discrimination task in the adult olfactory bulb. Eur. J. Neurosci. 24: 3578-3588.

Mayer, P., Wurch, T., Pauwels, P.J., Martel, J.C., Marien, M., and Imbert, T. 2001. Biological evaluation of the $\alpha_{2}$ antagonist dexefaroxan and its analogs for the treatment of neurodegenerative diseases. Abstracts of the 221st National Meeting of the American Chemical Society, San Diego, CA, 1-5 April 2001.

Mayer, P., Piedecoq, C., Brunel, P., Imbert, T., Chopin, P., Martel, J.C., Marien, M., Wurch, T., Pauwels, P., and Colpaert, F. 2003. Synthesis and biological evaluation of F 14413, an inverse agonist at $\alpha_{2}$-adrenoceptors with potential for the treatment of neurodegenerative diseases. Abstracts of the 2 nd Joint French-Swiss Meeting on Medicinal Chemistry, Beaune, France, 1-4 July 2003.

McCune, S.K., Voigt, M.M., and Hill, J.M. 1993. Expression of multiple $\alpha$ adrenergic receptor subtype messenger RNAs in the adult rat brain. Neuroscience 57: 143-151.

McLean, J.H. and Shipley, M.T. 1987. Serotonergic afferents to the rat olfactory bulb: I. Origins and laminar specificity of serotonergic inputs in the adult rat. J. Neurosci. 7: 3016-3028.

Montag-Sallaz, M. and Buonviso, N. 2002. Altered odor-induced expression of c-fos and arg 3.1 immediate early genes in the olfactory system after familiarization with an odor. J. Neurobiol. 52: $61-72$.

Moriceau, S. and Sullivan, R.M. 2004. Unique neural circuitry for neonatal olfactory learning. J. Neurosci. 24: 1182-1189.

Mouly, A.M., Elaagouby, A., and Ravel, N. 1995. A study of the effects of noradrenaline in the rat olfactory bulb using evoked field potential response. Brain Res. 681: 47-57.

National Research Council. 1996. Guide for the care and use of laboratory animals. Institute of Laboratory Animal Resources, Commission on Life Sciences, National Academy Press, Washington, DC.

Pauwels, P.J., Wurch, T., Tardif, S., Finana, F., and Colpaert, F.C. 2001. Analysis of ligand activation of $\alpha_{2}$-adrenoceptor subtypes under conditions of equal $\mathrm{G}_{\alpha}$ protein stoichiometry. Naunyn Schmiedebergs Arch. Pharmacol. 363: 526-536.

Rosser, A.E. and Keverne, E.B. 1985. The importance of central noradrenergic neurones in the formation of an olfactory memory in the prevention of pregnancy block. Neuroscience 15: 1141-1147. 
Sallaz, M. and Jourdan, F. 1996. Odour-induced c-fos expression in the rat olfactory bulb: Involvement of centrifugal afferents. Brain Res. 721: $66-75$.

Sirvio, J. and MacDonald, E. 1999. Central $\alpha_{1}$-adrenoceptors: Their role in the modulation of attention and memory formation. Pharmacol. Ther. 83: 49-65.

Sullivan, R.M., Stackenwalt, G., Nasr, F., Lemon, C., and Wilson, D.A. 2000. Association of an odor with activation of olfactory bulb noradrenergic $\beta$-receptors or locus coeruleus stimulation is sufficient to produce learned approach responses to that odor in neonatal rats. Behav. Neurosci. 114: 957-962.

Tellez, S., Colpaert, F., and Marien, M. 1999. $\alpha_{2}$-Adrenoceptor modulation of cortical acetylcholine release in vivo. Neuroscience 89: 1041-1050.

Tronel, S., Feenstra, M.G., and Sara, S.J. 2004. Noradrenergic action in prefrontal cortex in the late stage of memory consolidation. Learn. Mem. 11: 453-458.

van Veldhuizen, M.J., Feenstra, M.G., Heinsbroek, R.P., and Boer, G.J 1993. In vivo microdialysis of noradrenaline overflow: Effects of $\alpha$-adrenoceptor agonists and antagonists measured by cumulative concentration-response curves. Br. J. Pharmacol. 109: 655-660.

Veyrac, A., Didier, A., Colpaert, F., Jourdan, F., and Marien, M. 2005. Activation of noradrenergic transmission by $\alpha_{2}$-adrenoceptor antagonists counteracts deafferentation-induced neuronal death and cell proliferation in the adult mouse olfactory bulb. Exp. Neurol.
194: $444-456$.

Wilson, D.A., Pham, T.C., and Sullivan, R.M. 1994. Norepinephrine and posttraining memory consolidation in neonatal rats. Behav. Neurosci. 108: $1053-1058$.

Wirth, S., Lehmann, O., Bertrand, F., Lazarus, C., Jeltsch, H., and Cassel, J.C. 2000. Preserved olfactory short-term memory after combined cholinergic and serotonergic lesions using 192 IgG-saporin and 5,7-dihydroxytryptamine in rats. Neuroreport 11: 347-350.

Woo, C.C. and Leon, M. 1995. Distribution and development of $\beta$-adrenergic receptors in the rat olfactory bulb. J. Comp. Neurol. 352: $1-10$

Wood, P.L., Kim, H.S., and Altar, C.A. 1987. In vivo assessment of dopamine and norepinephrine release in rat neocortex: Gas chromatography-mass spectrometry measurement of 3-methoxytyramine and normetanephrine. J. Neurochem. 48: $574-579$.

Yuan, Q., Harley, C.W., and McLean, J.H. 2003. Mitral cell $\beta_{1}$ and 5-HT2A receptor colocalization and cAMP coregulation: A new model of norepinephrine-induced learning in the olfactory bulb. Learn. Mem. 10: 5-15.

Received July 19, 2007; accepted in revised form October 26, 2007. 


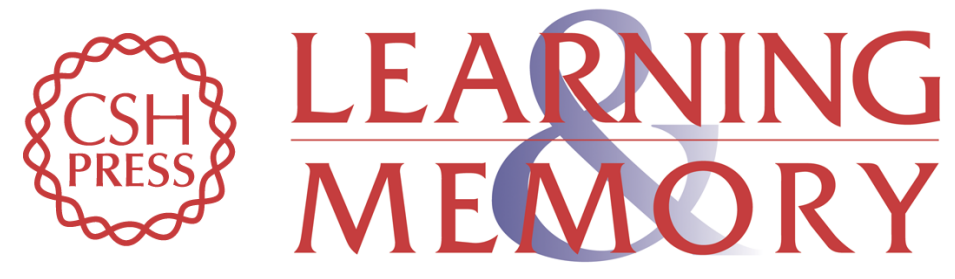

\section{Noradrenergic control of odor recognition in a nonassociative olfactory learning task in the mouse}

Alexandra Veyrac, Véronique Nguyen, Marc Marien, et al.

Learn. Mem. 2007, 14:

Access the most recent version at doi:10.1101//m.708807

References

This article cites 49 articles, 9 of which can be accessed free at:

http://learnmem.cshlp.org/content/14/12/847.full.html\#ref-list-1

License

Email Alerting

Service
Receive free email alerts when new articles cite this article - sign up in the box at the top right corner of the article or click here. 